\title{
School Networks and Sustainable Development
}

\author{
Simona Franzoni ${ }^{* *}$, Francesca Gennari $^{* * *}$
}

\begin{abstract}
The promotion of new approaches to the development of knowledge and the production of education services, which respect the Europe 2020 strategies, is the precondition for the economic development of the entire country, upholding the principles of inclusion and sustainability. The scarcity of resources earmarked for the education system and the very complexity of learning needs suggest forms of institutional cooperation between schools and their stakeholders, which can only be achieved through networks of relationships. This article aims to highlight the conditions at the base of: the building and development of a network of relationships between the school and the community, so as to meet ever more complex educational needs; the maintenance and enhancement of relations in the network, with the aim of ensuring an effective system of educational services; the definition of responsibilities, structures and processes of school governance for the human capital's growth as part of the sustainable development of a local community.
\end{abstract}

Keywords: Network; Sustainability; Responsibility; School

\section{The School System and Sustainable Development}

The European Union has focused a great deal of attention on the reform of school systems, in order to guarantee every citizen access and opportunities to develop his or her potential and skills. The priority goal pursued by the EU is the transfer of the capacity to solve problems, so as to take an active part in the emerging knowledgebased economy and to strengthen social solidarity.

The Europe 2020 programme aims to help Europe to recover from the crisis and to emerge from it stronger than before, nationally and internationally, sustaining competition, productivity, economic growth and social cohesion. In the second decade of the century, Europe should be engaged in a project for social economics, based on priority goals that are closely linked to sustainable growth, through the promotion of an economy that respects the environment, and is efficient and competitive.

\footnotetext{
* The Authors: S. Franzoni $\S ~ 1,2$, F. Gennari $\S \S 3,4$

** Associate Professor of Business Economics, University of Brescia (sfranzoni@eco.unibs.it)

**** Assistant Professor of Business Economics, University of Brescia (fgennari@eco.unibs.it)
} 
Today the European education system is having to promote new models for the development of knowledge, and in particular to define new competences in the social and professional context. The mission of the entire European school system, of each nation in Europe and of each school in the various countries can be summed up as: to develop knowledge, skills, an aptitude for personal fulfilment and development, active citizenship, social inclusion and employment.

The main goal of schools and of the whole network that gravitates around the school system, is to develop 'basic knowledge' and universal skills which boil down to knowing how to read, write, etc. The framework of our schools is organised around the student and does not overlook his or her cultural and socioeconomic status. Well-trained, competent human resources are indispensable to foster the development of a knowledge-based economy and to promote the innovation that is necessary in this regard.

Schools should also influence the student's overall education process, instilling aspirations and convictions that make him an ethically correct person oriented to sustainable development. It is all about promoting so-called 'transverse competences' such as a sense of responsibility, autonomy, creativity that can be expressed in various contexts, and organisational and relationship skills. And finally, the growth of individual human capital is an advantage for local, national and international societies and, therefore, for the whole community, suitably complemented by the numerical and literary knowledge/skills/competences transferred during training. In this regard, "the combination of knowledge, skills and attitudes appropriate to the context" becomes significant, represented by the "eight key competences for lifelong learning": communication in the mother tongue, communication in foreign languages, mathematical competence and basic competences in science and technology, digital competence, learning to learn, social and civic competences, spirit of initiative and entrepreneurship, cultural awareness and expression (European Recommendation 2006/962/CE).

" "Communication in the mother tongue" is the ability to express and interpret concepts, thoughts, feelings, facts and opinions in both oral and written form and to interact linguistically in an appropriate and creative way in a full range of societal and cultural contexts, in education and training, work, home and leisure. "Communication in foreign languages": broadly shares the main skill dimensions of communication in the mother tongue. It is based on the ability to understand, express and interpret concepts, thoughts, feelings, facts and opinions in both oral and written form in an appropriate range of societal and cultural contexts, in education and training, work, home and leisure. "Mathematical competence and basic competences in science and technology": mathematical competence is the ability to develop and apply mathematical thinking in order to solve a range of problems in everyday situations. Competence in science refers to the ability and willingness to use the body of knowledge and methodology employed to explain the natural world. Competence in technology is viewed as the application of that knowledge and methodology in response to perceived human wants or needs. "Digital competence": it involves the confident and critical use of Information Society 
Technology for work, leisure and communication. "Learning to learn": the ability to pursue and persist in learning, to organise one's own learning, including through effective management of time and information, both individually and in groups. "Social and civic competences": the former include personal, interpersonal and intercultural competence and cover all forms of behaviour that equip individuals to participate in an effective and constructive way in social and working life, and to resolve conflict where necessary. Civic competence equips individuals to fully participate in civic life, based on knowledge of social and political concepts and structures and a commitment to active and democratic participation. "Sense of initiative and entrepreneurship": refers to an individual's ability to turn ideas into action. It includes creativity, innovation and risk-taking, as well as the ability to plan and manage projects in order to achieve objectives. "Cultural awareness and expression": appreciation of the importance of the creative expression of ideas, experiences and emotions in a range of media, including music, performing arts, literature, and the visual arts. Cultural expression is essential to the development of creative skills, which can be transferred to a variety of professional contexts. A solid understanding of one's own culture and a sense of identity can be the basis for an open attitude towards and respect for diversity of cultural expression.

It is of significant importance to be able to include schools among sensitive and reliable partners, on a par with other local institutions, training human capital as part of the sustainable development of a local community.

The school unquestionably remains the central element of the education system. But the related activities are part of a complex network of relationships (Milward, Provan 2001; Sliwka 2003; Brondoni 2003; Kenis, Provan 2009, Klijn et al. 2010) that may be: vertical, with the relevant public system (Ministry and regional and local education authorities, Regional governments, local authorities, etc.), or horizontal, with reference to all the forces in a community (non-profit organisations, enterprises, universities, etc.) who are directly or indirectly interested in whether the quality of school results meets their expectations.

The article aims to examine how schools can find the interconnections and synergies necessary to foster the development of a network and the dissemination of knowledge in harmony with the dynamics of the socio-economic environment that they are part of. In particular, to foster the integrated development of services and to respond to the educational/formative needs of a local community where resources are scarce, schools need to be able to rely on extensive cooperation between the various bodies involved: families, the general public, local communities, universities, public authorities, companies and non-profit organisations.

The research questions are the follow: What are the conditions so that the network can function effectively? What are the basic elements on which the structure of the network is based? What are the responsibilities, structures and processes of school governance to support the network's development and working?

The considerations, show in the following paragraphs, make use of a knowledge base consisting of studies in the literature, surveys conducted by international 
organizations and by a recent empirical research (School Governance to build a Learning Community - a project with the support of the Lifelong Learning Programme of European Union) promoted by a group of European researchers (Salvioni et al. 2012; Franzoni, Gennari 2013).

\section{The Conditions for the Success of the School Network}

The school panorama is particularly complicated, because of both the complexity and variety of the needs of a given area, and the various elements (families, society, local community, universities, public authorities, enterprises and non-profit organisations) that play a well-defined role - in terms of the contribution they offer and of training expectations and needs.

This situation, combined with the gradual evolution of the school's crucial role in the economic development of a given area, makes it necessary to examine how schools can find the necessary interconnections and synergies to foster the development of a network and the spread of knowledge in harmony with the dynamics of the socio-economic environment that they belong to.

The creation of a school system that can build on the network of relationships with the various important players - network system - in the current context, seems to represent the most suitable way of saving its independence, and one that is also able to create synergies (Sliwka 2003; Caldwell 2009). The consolidation of paradigms related to the processes of institutional modernization have been significant factors in promoting the birth and development of networks in services, represented first by the New Public Management (Hood 1991) and later by the New Public Governance (Osborne 2010). In particular, the Public Governance (Kooiman, Van Vliet 1993; Rhodes 1996; Osborne 1998; Bovaird, Loffler 2002; Schedler 2003; Franzoni, Gandini 2010) concerns the role of Public Administration in networks. The networks are formed by public actors as well as non-profit organizations, enterprises and organizations as expressions of civil society in which the processes of dialogue and negotiation are activated in order to foster cooperation on the development of policies and services.

However, certain conditions need to be met so that the network can function efficiently. At this point we must:

- identify the elements that belong to the network - outline of the 'boundaries' of the network;

- specify the roles, functions and responsibilities of each one in relation to the agreed objectives (to avoid overlapping and gaps);

- define the rules for the functioning of the network and the means of participation;

- adopt tools that can foster cooperation and communication;

- identify the education needs of a community focused on lifelong learning: the development of the communication in the mother tongue and in foreign languages, mathematics, technology (basic competences); the adoption of attitudes that make the student a responsible person; the creation of new professional skills for the labour market; the prevention of the use of drugs; care of one's health, respect of the environment and in general the acquisition by the student of the values of active citizenship (transverse competences); 
- define control systems that can make it possible to measure the progress made towards the achievement of goals and to assess the system's overall effectiveness.

It therefore becomes essential to carry out a comparison between schools, between schools and families, and between schools, local authorities, non-profit organisations, businesses and society to define an integrated system of services that can guarantee:

- uniform control over the education system;

- the definition of school structures run by capable, competent managers;

- the involvement of important stakeholder in the joint planning and joint production of education services (OECD 2011; Unesco 2008);

- the accountability of all the network stakeholders.

$\square$ A recent analysis of relations between schools and the surrounding territory that considered five countries in the European Union (Italy, Greece, Sweden, Netherlands and Romania) and five categories of stakeholder (principals, teachers, students, parents and other stakeholders - businesses, local authorities, cultural associations) reveals on one hand the current weakness of relations between schools and their stakeholders and on the other, the necessity and importance of establishing positive relations between all the local players where education/training policies are concerned. The research highlights certain differences in the response with reference to the different classes of stakeholder interviewed. There may be many explanations for this behaviour, first of all related to the different level of involvement of each specific class in the decision-making process, in the development of activities and in the perception of the relationship between needs, activities and results. It emerges that the integration between the school and the surrounding area depends first and foremost on the territorial context and the culture that it expresses, the level (primary, secondary, etc.) and type of schools involved (technical/profession institutes or high schools), and the personal commitment of the principal.Regarding the level of change necessary to achieve local integration and cooperation, the stakeholders interviewed gave answers that varied according to their category and nationality. However, the recurrent opinions regarded (Franzoni, Gennari 2013):

- improving communication between the school and the surrounding area. This would increase awareness among the community of the role that schools play in the local area, while schools could be more proactive towards the growing needs of the community, exploiting territorial resources better;

- opening the school doors, making certain services (canteens, libraries, gyms, etc.) available to the local community;

- improving the tools of decentralised management, removing bureaucratic constraints and capitalising on processes to increase integration between schools, local communities and stakeholders.

In the school system, the basic elements on which the structure of the network is based are (Salvioni et al. 2012): 
1. the network 'hubs', i.e.: schools (represented by their principals), students, parents, teachers, administrative staff, school boards, local authorities, enterprises, hospitals, non-profit organisations, etc., which make up the network and enable it to 'live' autonomously and to communicate with other systems to exchange values and information.

The main players can be classified as:

- internal players, in other words those who directly and continuously exercise responsibility in the school context through their decisions and actions, helping to outline the development strategies and ways of achieving results (output and outcome). They are the bodies that run the school, the teaching staff, technical and administrative employees, etc.;

- external players, those who are basically the beneficiaries of the activities performed by the schools. The community in general, which has a variety of interests invested in schools;

- 'co-makers', i.e. entities which, as an effect of the type of relationship they establish with schools, tend to reveal a particular approach to the total or partial sharing of economic risk and social effectiveness (Brondoni 2002). These co-makers are: the Ministry of Education and its peripheral offices, regional governments, local authorities, students, families, enterprises, nonprofit organisations, etc.

Because of the role schools play in training human capital, the class of co-makers that usually comprise the reference network is particularly broad, and reflects the fact that the quality of school results conditions the development of the entire economic and social system.

2. The 'connections', i.e. the links that make the transmission and dissemination of the information elements developed by each hub possible inside the network. In order to maintain the connection system, a constant flow of communication needs to evolve between the network hubs. This is indispensable for the spread of homogeneous, shared information and to effectively integrate the various forces in the network. This connection system is achieved with appropriate IT support and effective procedures. Basically, this means understanding 'why' and 'how' schools relate to each individual player in each area of the eight key competences.

The intensity of the relationship is defined subsequently on the basis of the importance of each player, and ways of strengthening this relationship are identified, if it is strategic.

3. The 'codes', the 'rules' and the 'methods' that define the way the network functions. These refer to both behavioural factors (language, codes, values, etc.) and procedural factors. As a matter of fact, it is only a common language that makes it possible to codify the knowledge of each hub and to spread it through the network connections. It is also important that the network hubs should share the operating methods, values and rules of interaction. This also makes it possible to establish and develop effective joint service production processes among the elements of the network (families, civil society, enterprises, third sector, etc.). At this stage, it is important to identify the means of sharing the rules and knowledge and ways of strengthening links between the hubs, for example by: meetings, round tables, focus groups, digital information systems, the Internet, etc. It will subsequently be necessary to identify the information to share (mission, goals, results, etc.), the frequency and the most suitable transmission channel for each 
type of information selected. And finally, we have to define how to regulate the behaviour of the players in the network with informal mechanisms or a formal approach: behaviour codes and charter of values, informal agreements, framework agreements, project agreements, conventions, network contracts, etc.

Strengthening the network system makes it easier for schools to pursue an effective system offering intervention and services managed with criteria of efficiency and economy, in order to guarantee balanced and transparent use of resources. In fact, the application of network models and their management could enable individual organisations (which are part of the network) to enjoy significant benefits in terms of the rationalised use of their own resources, following the exploitation of economies of scale and economies of learning to pursue the principle of economy. What is more, in contexts where a large number of comakers are present, cooperation highlights the strategic determination of the organisations to ensure a lasting and sustainable future. Capabilities and attitudes that strive to develop and promote positive relations with the stakeholders with whom advantages and/or disadvantages are shared, related to the quality of the results, therefore acquire a strategic, substantial significance for economic and social development.

Schools must create and foster the development of conditions that allow the culture of the region as a whole to evolve and be enriched, in harmony with the dynamics of the socio-economic environment that the local community belongs to.

In this context, the network exploits fruitful interaction among the subjects present to improve its focus on the significant variables and the critical factors of success, which are thus linked to an ability to effectively manage: relations with all the stakeholders, which generate indices and targets for the satisfaction of learning (social success); the achievement of optimal conditions to exploit available economic resources, which generate the quantitative-monetary targets and indices (economic success); comparison with other operators in the education system and qualification of one's own image in the environment, which generate competitive targets and indices (competitive success).

As a result, schools will not remain mere providers of services but will be able to recover their own values such as an orientation and aptitude to stimulate the ability to meet the expectations expressed by society.

\section{The Responsibility and Performance of Schools}

The renewed role played by schools focuses on another issue: the need to identify the conditions at the base of governance structures and processes that support networks' development and operation in order to promote socio-economic progression of the entire community.

A strong cultural change is demanded of schools, of both their organisation logics and the management of their resources, questioning and adapting responsibilities, systems and operating practices. We could say that this evolution is the precondition for pursuing lasting a socio-economic balance.

The capacity to respond appropriately to the educational and social expectations made of schools certainly benefits from the creation of networks in which the efforts of the various forces are catalysed around common, priority objectives, which are suitably honed to specific contributions. In other words, schools should 
stimulate the activation of processes to orient behaviour, both within organisations and between organisations (networks), with respect to essential and prevalent macro objectives by activating suitably elaborated and shared information flows.

Schools' ability to identify the expectations of the players (students first and foremost) that converge on the school is the first step in the process to offer education services that are both consistent with the needs expressed and privileged beneficiaries of the available resources (Faubert 2012).

The effective and efficient identification and therefore the satisfaction of the training expectations makes a considerable contribution to the economic development of the entire area (OECD 2010), considering that the social and economic cost of unsuitable services imply early school leaving in the short term and, in the medium-long term, situations of: growing criminality, a loss of social cohesion, poor civic sense, high unemployment, lower tax revenues (Dowrick, Crespo 2007; Psacharopoulos 2007).

- In 2010, OECD countries spent an average of $6.3 \%$ of their GDP on educational institutions $(6.5 \%$ if we include private sources of funds). Expenditure (all levels combined) was greater than 6\% in nearly half of the countries considered, and even above $7 \%$ in seven of them: Denmark (7.9\%), Iceland (7.7\%), Israel (7.4\%), Korea (7.6\%), New Zealand (7.3\%), Norway (7.6\%) and the United States (7.3\%). At the other end of the spectrum, five countries spent less than 5\% of their GDP on education, namely the Czech Republic (4.7\%), Hungary (4.6\%), Italy (4.7\%), the Russian Federation (4.9\%) and the Slovak Republic (4.6\%). (OECD 2013).

The scarcity of resources, accentuated by the current economic crisis, underlines the evolutionary trend towards forms of school management that are shaped around corporate economic logics with the goal of harmoniously combining social goals, a managerial orientation that respects the principle of efficiency and optimised results.

The chief goal of the adoption of an active managerial approach, to be achieved consistently with respect to existing legislative constraints and to the need to position schools in the area, is to guarantee the coordinated reconciliation of the priority social dimension with an economic dimension, in terms of the use of resources to produce education services.

Schools pursue institutional goals related to the appropriate satisfaction of a collective need (education) through the use of resources and according to definite rules of behaviour, based on conditions of: effectiveness (the capacity to satisfy the needs expressed by stakeholders with services of an appropriate quality), efficiency (optimising the allocation of resources), and economy (performance of the activity in such a way as to guarantee the durability and independence of the educational institution). Effectiveness, efficiency and economy are essential operating conditions for any institution and they are strictly inter-related, in fact excessive emphasis on only one of the conditions mentioned above can imply situations that are less than optimal and consequences of no little importance for the entire system.

What emerges is the need to appropriately and fairly reconcile a social dimension, linked to the choice of the education service offered, with an economic dimension related to its production. 
In detail, the social connotations are linked to the prevalent need to satisfy typically social and collective needs, and represent an institutional attribute of schools, which must inspire all behaviour within the organisation, in relation to which the results obtained must be assessed.

At the same time, the economic aspect guarantees the activation of a virtuous cycle in which the effective and efficient use of scarce resources to satisfy training expectations is qualified on the basis of the lasting survival of the school. The striving for economic stability represents a strategic criterion of the institution which is responsible for obtaining and using the necessary resources to achieve results that can justify the reinstatement of the resources necessary to continue their activities.

It therefore becomes imperative to combine schools' social responsibilities with economics, acquiring the necessary consensus to the activation of a virtuous circle of the collection of resources, the use of the same and the results obtained by satisfying the needs of the community.

The above presupposes the evolution of the managerial approach of schools in which profound changes combine, particularly in countries where education is seen as a service provided as a rule by the public authorities. These changes should foster:

- the identification of the critical factors that can significantly influence the institution's economic situation, on the basis of expectations expressed by the forces in the network and of the services provided;

- the rationalisation of service production activities by the definition of decision-making environments, responsibilities and means of integration between the various deciding organs inside the network;

- the implementation of managerial support mechanisms that are consistent with the degree of complexity of the educational establishment and able to sustain: the identification of expectations, the collection and allocation of the resources necessary to produce the services that can satisfy said expectations, and the assessment of the results obtained;

- processes of cultural change and training focused on sharing common objectives in the network and the awareness by each involved player of active participation in their realisation.

This is borne out by the fact that the level of privatisation of educational institutions depends on a perception of the balance between social aspects and economic aspects, but also on the organisational and strategic complexity of the institutions themselves, which in turn are constrained by the existing legislation (national education system) and the requirements deemed necessary for the development of effective, quality management.

With regard to the logics behind the different national education systems, the need to optimise the efficiency of public spending is gradually generating decentralisation policies that can influence both the organisational set-up and the number and combination of the services offered in the medium term.

$\square$ Over $85 \%$ of expenditure on education by the 27 countries in the European Union is publically funded and the envisaged budgets can justifiably be considered as an indicator of their education spending policies. In 2012, the most significant budget decrease is evident in 
Cyprus, at almost 15\%. Greece, Latvia, Lithuania and the United Kingdom had almost a 10\% decrease in 2012 compared to 2011. Italy, Portugal and Croatia displayed a decrease of around 5\%. And budgetary reductions in education are likely to continue in some countries in the near future. Where the priorities of national policies are concerned, while many countries continue to invest in education, there are also significant references to more efficient use of resources and an improvement in administrative processes. (European Commission/EACEA/Eurydice 2013).

Generally speaking, the concept of decentralisation is linked to the vertical delegation of the related decision-making capacity to roles within an organisational system (Mintzberg 1979; Brown 1990; Rondinelli et al. 1984; Manor 1999, Ribot 2002).

In the education system, decentralisation is a particularly complex phenomenon, the effect of the differences inherent in national legal systems, the roles formally involved, but also proxy participation mechanisms (Slater 1993; Kemmerer 1994; Lundgren 2001; Daun 2011). In this context, the concept of School Business Management (SBM) has gradually evolved over the years, defined as the sharing of decision-making powers between the various players involved in the education system (Marburger 1985). The Authors have interpreted this concept differently, seeing it as the sharing of choices regarding the allocation of ring-fenced public resources (Caldwell, Spinks 1988) or as the actual transfer of decision-making powers and related responsibilities to schools and their stakeholders (Malen et al. 1990; Murphy 1997).

$\square$ European countries differ with regard to the organisation of output, the cultural homogeneity of the population, religious beliefs and the public system. This diversity explains the peculiar nature of their respective education systems, in spite of an evident trend to convergence due to globalisation.

Comparative analysis carried out in 2010-2012 (School Governance to Build a Learning Community - Comenius Multilateral Projects Sgolc Project has been funded with support from the European Commission) in a number of Northern (Netherlands and Sweden), Eastern (Romania) and Mediterranean European countries (Italy and Greece) revealed that everywhere the State plays a leading role as: an entity able to define general guidelines that can pilot the education policies of the other levels of the public administration; the entity responsible for the funding of the entire education system; external assessor of the quality of the service provided by schools. All the countries analysed revealed a more or less advanced degree of decentralisation, but effective decision-making autonomy for schools was only evident in the Netherlands (where educational establishments enjoy a certain amount of freedom in the definition of school curricula, albeit in line with guidelines from the Ministry, and in the recruitment of human resources) and in Sweden (where schools choose their own teachers and receive significant funding from the region where they are located). In Romania, Italy and Greece, on the other hand, school 
independence is formal (recognised by current legislation) rather than substantial, because it is limited to partial aspects regarding teaching methods and the organisation of the service. The result is that, while Northern countries have for some time undertaken the road of the managerialisation of the school system, because of legislative and cultural constraints, the other countries analysed must still start the process of full appropriation of business logics with particular regard to the definition of priority objectives and the related gathering and allocation of the financial and human resources necessary to achieve them (http://eacea.ec.europa.eu/education/eurydice/).

Policies based on the decentralisation and devolution of decision-making powers imply the revaluation of relations between schools and their stakeholders in the territory which, although led by students who remain the focal point of the entire education process, spread significantly into an evolved concept of the satisfaction of education requirements. The result is a careful evaluation of the suitability of the complexity of educational establishments and related governance needs.

The degree of organisational complexity depends on the roles and responsibilities assigned, which also prompts behaviour in terms of decisions and actions. In this context, the trend to increasingly bureaucratise educational establishments is based primarily on redefining the role of the school principal who, in relations with the stakeholders, represents the management of the institution he or she runs.

The new role of the school in the network of players, relations and resources, to foster the territory's social and economic development, entails a suitable governance structure, which is able to identify the priority goals and to catalyse efforts towards the achievement of the same.

$\square$ In European countries where decentralisation takes the form of the effective management of human and financial resources by schools (in respect of real school independence), the sharing of priority objectives and the participation of the various stakeholders according to their roles and responsibilities are expressed actively. However, in those countries where school independence is only formal and strongly limited, the stakeholders take little part in decision-making processes: decision-making power is concentrated in the principal, the formal expression of the devolution of authority in the broader public administration. However, everywhere it is the stakeholders (teachers, students and their families, representatives of the business world and of associations) that clamour for a more inclusive role and greater involvement in decisions related to the education process, aware that it cannot be limited to the closed environments of educational establishments (Franzoni, Gennari 2013).

The presence of leading figures, with pedagogical and managerial skills, is an essential condition for the balanced realisation of the socio-economic dimension of education services. In many European countries, the re-examination of the role of the school principal is an important key to a non-traumatic approach to the challenges of globalisation, bringing both the organisational complexity and the strategic complexity of educational establishments into line with the priority 
conditions of sustainable development. In fact, because the strategic complexity can be linked to the number of education services offered in response to the needs expressed by external players, it defines the characteristics of the network of relations with them.

On the other hand, the stakeholders themselves demonstrate the need for better defined roles, for greater participation and for school leaders who are able to guide numerous entities towards shared objectives, on the basis of an awareness of education systems perceived as obsolete in their organisation and/or what they offer.

$\square$ In spite of the diversity between the education systems of the European countries under examination, the School Governance to Build a Learning Community research has revealed a common orientation towards the competences that current school leaders should possess in order to offer quality services that are consistent with the education needs expressed by the local community, simultaneously optimising the available resources. The stakeholders interviewed (current school principals, students, teachers, families and representatives of other categories such as associations, business, etc.) look forward to the formation of managerial figures with skills in the following areas (Franzoni, Gennari 2012):

- leadership: experience built up in complex organisations, visibility, self-assessment, prompt decision-making, impartiality, prestige, tendency to meritocracy, honesty, emotional intelligence, shrewdness, patience, reliability, stability, capacity to inspire, charisma, curiosity, team building skills;

- managerial skills: stimulus to participation, networking skills, ability to delegate, assessment and reporting skills, familiarity with standards and organisational processes, understanding of financial management and human resources management;

- pedagogy: pedagogical competence, capacity to innovate, familiarity with curricula and programmes.

\section{Conclusions}

The evolution of education needs underlines the necessity of exploiting relations with the stakeholders who, in various capacities and in respect of their roles, are involved in satisfying these needs. The quality of the education services is the result of a transverse process, which involves a wide range of subjects and reveals its impact in the medium-long term, being closely linked to a country's economic development and, therefore, to an improvement in the wellbeing of the entire community.

The central role played by schools, not only in society but also in a country's economy, underlines the joint consideration of aspects of social life and economics as fundamental dimensions for the identification and the production of education services. The integration of these dimensions underlines the need to focus more attention on the economic aspects of social phenomena that are still of fundamental importance in a school's institutional function. To foster the knowledge of and 
conscious participation in the achievement of priority objectives and those of significance for the community, but respecting a view of convenience and economic balance, criteria of motivation, sharing and the assessment of decisions and actions.

Full awareness of the concept of the school as an establishment that performs an economic activity therefore accompanies the expression of governance founded in economics, the correct use of the limited resources available, even through a constructive comparison between the various players actively involved in the education process within the broader school system. A fairer, more efficient use of resources is certainly the foundation for the enhancement of relations with stakeholders and the related activation of networks that focus strongly on realising priority objectives.

\section{Bibliography}

Bovaird Tony, Loffler Elke (2002) Moving from Excellence Models of Local Service Delivery to Benchmarking of 'Good Local Governance', International Review of Administrative Sciences, vol. 68 , n. 1, pp. 560-590.

http://dx.doi:10.1177/0020852302681001

Brondoni Silvio M. (2002) Global Markets and Market-Space Competition, Symphonya. Emerging Issues in Management (symphonya.unimib.it), n. 1, pp. 28-42. http://dx.doi.org/10.4468/2002.1.03brondoni

Brondoni Silvio M. (2003) Network Culture, Performance \& Corporate Responsibility, Symphonya. Emerging Issues in Management (symphonya.unimib.it), n. 1, pp. 8-24. http://dx.doi.org/10.4468/2003.1.02brondoni

Brown Daniel J. (1990) Decentralization and School-Based Management, Falmer Press, Bristol.

Caldwell Brian, Spinks Jim M. (1988) The Self-Managing School, Falmer Press, Lewes.

Caldwell Brian (2009) The power of Networks to Transform Education: an International Perspective, Specialist Schools and Academies Trust, London.

Daun Holger, Mundy Karen (2011) Educational Governance and Participation: Focus on Developing Countries, Report 120, Institute of International Education, Stockholm University.

Dowrick Peter, Crespo Natalie (2007) School failure, Handbook of Adolescent Behavioral Problems, Behavioral Science, Springer, London.

European Commission/EACEA/Eurydice (2013) Funding of Education in Europe 2000-2012: The Impact of the Economic Crisis. Eurydice Report. Luxembourg: Publications Office of the European Union.

Faubert Brenton (2012) In-school Policies and Practices for Overcoming School Failure: A Literature Review, OECD Education Working Paper, OECD Publishing, Paris.

Franzoni Simona, Gandini Giuseppina (2010) A governance Model for Managing Social and Educational Service, paper presented at 32nd EGPA Annual Conference, 8-10 September, Toulouse, France.

Franzoni Simona, Gennari Francesca (2012) School Leaders' Competencies to Build Learning Communities, 4th Annual International Conference on Education and New learning Technologies, 2-4 July, Barcelona, Spain.

Franzoni Simona, Gennari Francesca (2013) School Governance. An International Comparison, USChina Review B, vol. 3, n. 10, pp. 772-779.

Hood Christopher (1991) A Public Management For All Seasons?, Public Administration, vol. 69, n. 6, pp. 16-45.

http://dx.doi:10.1111/j.1467-9299.1991.tb00779.x 
Kemmerer Fred (1994) Decentralization of Schooling in Developing Nations, in Thomas Husén, Norman Postleithwaite (eds), International Encyclopedia of Education, Pergamon Press, Oxford, pp. 1412-1416.

Klijn Erik H., Steijn Bram, Edelenbos Jurian (2010) The Impact of Network Management Strategies on the Outcomes in Governance Networks, Public Administration, vol. 88, n. 4, pp. 92-123. http://dx.doi.org/10.1111/j.1467-9299.2010.01826.x

Kooiman Jan, Van Vliet Martijn (1993) Governance and Public Management, in Kirsten A. Eljassen, Jan Kooiman, Managing Public Organisations: Lessons from Contemporary European Experience, Sage Publication, London, pp. 240-267.

Lundgren Ulf (2001) Governing the Education Sector. International Trends, Main Themes and Approaches, Institute for Educational Policy: Governance for Quality of Education, Conferences Proceedings, The Open Society Institute \& World Bank, Budapest.

Malen Betty, Ogawa Robert, Kranz Joe (1990) What Do we Know about Site-based Management: a case Study of the Literature - A call for Research, in R. Clune, F. White, Choice and Control in American Education: the Practice of Choice, Decentralization and School Restructuring, Falmer Press, London.

Manor James (1999), The Political Economy of Democratic Decentralization, World Bank, Washington D.C.

Marburger, Carl L. (1985), One School at a Time, National Committee for Citizens in Education, Columbia.

Mintzberg Henry (1979), The Structuring of Organizations: A Synthesis of the Research, PrenticeHall, Englewood Cliffs.

Milward Brinton H., Provan Keith G. (2001) Do Networks Really Work? A Framework for Evaluating Public-Sector Organizational Network, Public Administration Review, vol. 61, n. 4, 2001, pp. 79-96. http://dx.doi:10.1111/0033-3352.00045

Murphy Joseph (1997) Restructuring Through School-Based Management, in F. Townsend (ed). Restructuring and Quality: Issues for Tomorrows Schools, Routledge, London, pp. 35-60.

OECD (2010) Overcoming School Failure: Policies that Work, OECD Publishing, Paris.

OECD (2011) Public Governance Reviews. Together for Better Public Services. Partnering with citizens and civil society, Oecd Publishing, Paris.

OECD (2012) Equity and Quality in Education: Supporting Disadvantaged Students and Schools, OECD Publishing, Paris.

OECD (2013) Education at a Glance 2013: OECD Indicators, OECD Publishing, Paris.

Osborne Stephen P. (2010) The New Public Governance? Emerging Prospectives on the Theory and Practice of Public Governance, Routledge, London.

Osborne Stephen P. (1998) Voluntary Organisations and Innovation in Public Services, Routledge, London.

Kenis Patrick, Provan Keith G. (2009) Towards an Exogenous Theory of Public Network Performance, Public Administration, vol. 87, n. 3, pp. 440-456. http://dx.doi:10.1111/j.1467-9299.2009.01775.x

Psacharopoulos George (2007) The Costs of School Failure, A Feasibility Study, Analytical Report prepared for the European Commission.

Recommendation of the European Parliament and of the Council of 18 December 2006 on Key Competences for Lifelong Learning (2006/962/EC).

Rhodes Robert (1996) The New Governance: Governing without Government, Political Studies, vol. 44, n. 4, pp. 652-667. http://dx.doi:10.1111/j.1467-9248.1996.tb01747.x

Ribot Jesse (2002) Democratic Decentralization of Natural Resources. Institutionalizing Popular Participation, World Resource Institute, Washington.

Rondinelli Dennis, Nellis John R, Cheema Shabbir, Decentralization in Developing Countries: A Review of Recent Experience, World Bank, Washington, D.C., 1984. 
Salvioni Daniela M., Gandini Giuseppina, Franzoni Simona, Gennari Francesca (2012) School Governance: the Roles of Key Actors, US-China Review B, vol. 2, n. 10, pp. 881-897.

Schedler Kettiger (2003) Public governance: Politische steuerung und public management. Switzerland: Universitat St. Gallen.

Slater Robert O. (1993) On Centralization, Decentralization and School Restructuring: A Sociological Perspective, in Heric Beare, Loren Boyd (eds.), Restructuring Schools. An International Perspective on the Movement to Transform the Control and Performance of School, The Falmer, London, pp. 174-183.

Sliwka Anne (2003) Networking for Educational Innovation: A Comparative Analysis, Published in Networks of Innovation, OECD/CERI, Paris.

Unesco (2008) A Framework for Action on Education Governance, Recommendations of the Conference on Governance in Education: Transparency, Accountability and Effectiveness, Paris. 